\title{
TERCEIRA IDADE E TECNOLOGIA
}

\section{Propiciar ao idoso a oportunidade de adaptar-se, sem medo, às novas tecnologias disponíveis no cotidiano é atividade que ganha destaque entre pesquisadores e centros universitários}

Esta pesquisa originou-se no Centro de Cibernética Pedagógica', da Escola de Comunicações e Artes da Universidade de São Paulo, coordenado pelo Prof. Dr. Osvaldo Sangiorgi, orientador da Dissertação de Mestrado da autora, A Terceira Idade e a Sociedade Informatizada, premiada na Intercom/95, que teve por objetivo tratar do aprendizado dos princípios da informática e da utilização de computadores por indivíduos da terceira idade. Através de pesquisas e contínuo estudo dos resultados de questionários e entrevistas, a pesquisadora inferiu que:

1) não se dá por vontade própria do idoso o fato de ele não ter inicialização à informática;

2) há consciência por parte da população de terceira idade da importância da informática e da necessidade de ambientação com equipamentos computadorizados para uma perfeita integração à sociedade, caracterizando-se o computador como mais uma forma de comunicação e intercâmbio;

3) existe a expectativa, capacidade e disposição inconteste das pessoas de terceira idade de serem usuários e de terem real domínio de todos os dispositivos lastreados na informática pois, no mundo atual, quem detém a informação, detém o poder de cidadão.

Portanto, devido à informatização crescente da sociedade contemporânea, seus membros devem, necessariamente, tornarse possuidores destes conhecimentos. A terceira idade, por já ter passado pelos bancos escolares, irá buscá-los em outros lugares ou de formas diferentes das tradicionais.

Procurou-se, dentro de um enfoque cibernético, estabelecer as maneiras mais adequadas de ministrar estes conhecimentos de informática para os integrantes da terceira idade, bem como destacar os principais interesses deles como usuários e alunos nessa área.

\section{OS AUTORES}

\section{Aldete Büchler Zorrón Berlinck}

Professora Assistente na área de Informática da Universidade de Taubaté/ SP. Pesquisadora do Centro de Cibernética Pedagógica da ECA-USP.

E-mail: abzberli@belasartes.br

\section{José Augusto Mattos Berlinck}

Professor coordenador da Faculdade Aberta da Terceira Idade da Faculdade de Belas Artes de São Paulo e pesquisador do Centro de Cibernética Pedagógica da ECAUSP.E-mail: jberlink@usa.net

1. Centro de Cibernética Pedagógica do Departamento de Comunicações e Artes da ECA-USP - Av. Prof. Lúcio Martins Rodrigues, 443 - Cidade Universitária - CEP 05508-900 - São Paulo, SP. Tel: (011) 818-4372, fax: 818-4326. Membro efetivo da Associação Internacional de Cibernética - Namur, Bélgica. 
É direito do idoso, como cidadão, ter amplamente facilitado o seu acesso às novas tecnologias de informação, cabendo às instituições educacionais públicas $\mathrm{e}$ privadas, empresas, sindicatos e aos meios de comunicação em geral o dever de pesquisar e propiciar a concretização deste direito.

\section{VIVER BEM A LONGEVIDADE}

Hoje, $7 \%$ da população do país têm mais de 60 anos e até o ano 2025 os idosos serão 34 milhões ${ }^{2}$.

"Nos últimos quatro anos o município de São Paulo registrou 246 mortes de pessoas com mais de 100 anos, a mais velha das quais, uma chinesa de 118 anos de idade, morreu em 1994. A estatística é do Serviço Funerário Municipal, que está comprovando na prática, a tese dos demógrafos acerca do envelhecimento da população"3.

A sociedade atual envelhece rapidamente, com uma mudança significante em sua dinâmica demográfica e com efeitos conseqüentes na estrutura das classes sociais, no relacionamento Estado-Sociedade Civil, na cultura, no cotidiano, no mercado de trabalho.

Para viver bem, além de se cultivar hábitos saudáveis de alimentação, esporte e higiene desde a infância, deve-se envelhecer cultivando objetivos, sabendo adaptar-se ao meio, compreendendo limitações e comunicando-se. O meio atual é cada vez mais informatizado e as trocas de informação estão se realizando com características e técnicas diversas. Por isso, acre- dita-se que o relacionamento do idoso com estas tecnologias pode ser benéfico. Assim, a tecnologia passa a ser saber para um fazer melhor.

\section{ADMIRÁVEL E IRREVERSÍVEL MUNDO NOVO}

Tecnologia da Informação é o nome que se dá às máquinas que processam informações. Isso inclui gravadores de vídeo, telefones, calculadoras, caixas registradoras, equipamentos médico-eletrônicos e, claro, computadores.

Eles são provavelmente a forma mais versátil de tecnologia da informação. As crianças são melhores do que os usuários adultos para a manipulação de jogos e passatempos, realizado-os com prazer e com visível melhoria de suas atividades motoras e lógicas.

Tal fato não surpreende, pois as crianças ao nascerem já encontram um mundo computadorizado e, portanto, não se atemorizam e nem ao menos consideram tais máquinas como complicadas. As crianças normalmente encaram robôs e computadores com naturalidade.

O mesmo não ocorre com os adultos que, muitas vezes, se sentem constrangidos perante um caixa automático de banco, ou ainda, atrapalham-se com o temporizador programável de um sofisticado modelo de videocassete. Ora, isto é natural. Em ambos os casos o que mais pesa é uma barreira cultural que deve ser derrubada. Não se deve temer pedir informações e anotá-las se preciso for. É prático acostumar-se a estudar os manuais das máquinas que se adquirem,

2. Dados fornecidos pela PUCCAMP (Pontíficia Universidade Católica de Campinas), em junho de 1992.

3. QUEIROZ, Luís Roberto de Souza. Longevidade - estatística comprova aumento de idosos em SP. O Estado de S. Paulo. Caderno 2. São Paulo, 15 de junho de 1996. p.5. 
pois a operação desses equipamentos realmente não é tão natural para as gerações anteriores quanto é para as crianças.

Com respeito à operação de caixas automáticos de agências bancárias, indaga-se às pessoas o porquê de teimarem em permanecer em fila se poderiam solucionar com mais rapidez os seus afazeres, utilizando máquinas. A grande maioria responde que as máquinas são muito mais impessoais, que eles preferem falar com a pessoa do caixa, dizer bom dia e sorrir. Um outro grupo, de comportamento declaradamente convencional, não parece possuir uma atitude otimista com a própria longevidade.

Sem dúvida, a necessidade de comunicação homem-homem parece tomar dimensões de grande importância para os idosos, que freqüentemente manifestam indícios de carência afetiva. Mas, também há a possibilidade de se ampliar contatos pessoais através do computador, permitindo que se possa visualizá-lo como uma verdadeira janela para o mundo.

Nas sociedades mais adiantadas e ricas, várias pessoas fazem uso de seus micros pessoais para se comunicarem com os amigos distantes ou impossibilitados de se locomoverem. Isto é realizado através das redes de computadores, como a Internet. Os micros são também responsáveis pelo lazer de inúmeras pessoas que, além de utilizarem o seu potencial prático, com eles se divertem utilizando uma grande variedade de software de jogos.

Pesquisas têm mostrado que, nos EUA, mais da metade das crianças na primeira idade possuem computadores em casa e que seus avós se interessam em aprender determinados jogos para poderem brincar com elas.

A partir dessa iniciação os idosos sentem-se mais à vontade para fazerem uso de outras atividades computadorizadas. Tor- nando-se donos de microcomputadores, sentem-se mais motivados a aprender os aplicativos básicos, substituindo gradativamente suas máquinas de escrever, agendas de compromisso etc.

Um fato que não se pode deixar de mencionar é o preconceito, pois, na verdade, torna-se difícil saber conviver com pessoas que apresentam determinados tipos de limitações. Por vezes, lamentavelmente, encara-se o idoso como deficiente, pelo simples fato de terem restringidas algumas das habilidades que possuíam na juventude. A maioria normalmente não percebe que estas limitações podem ser tornadas mais amenas, bastando que se usem estratégias que lhes sejam pertinentes. Trata-se, afinal, de um simples fato de adaptação. Sobre tais problemas, na grande maioria das vezes, o próprio idoso apresenta boas soluções, como por exemplo:

- para aqueles que têm dificuldade na utilização de dispositivos do tipo mouse, existe a alternativa do teclado, que deve ser grande o bastante para que possa oferecer maior comodidade de uso (para o caso de dificuldades motoras mais graves);

- para aqueles com certa limitação visual, a solução pode ser a utilização de código de cores ou sonorização;

- para aqueles que se sentem pressionados na utilização de máquinas comunitárias, oferecê-las na opção de biombos individuais.

\section{CURSOS, OFICINAS E FACULDADES PARA A TERCEIRA IDADE}

Ao se falar em Faculdade ou em escola, imediatamente se está fazendo uma aproximação com os meios tradicionais de ensino. Assim sendo, chamá-las de Faculdades 
da Terceira Idade ${ }^{4}$, sem que se dê conta, estão se estabelecendo padrões de ensino comparáveis aos ministrados nas escolas tradicionais de terceiro grau, evidentemente sem que seja dada ênfase ao rigor de ensino daqueles cursos. Fundamentalmente, tem-se visto nas Faculdades da Terceira Idade um revezamento de palestras que versam primordialmente sobre a saúde do idoso, seu comportamento, como deve agir etc., esquecendo-se de que o integrante dessa faixa etária não tem apenas a necessidade de adquirir conhecimentos para um agir futuro. Necessita primordialmente de um agir imediato, que the possibilite estar em contato com os avanços tecnológicos do instante, permitindo-lhe sua plena utilização.

Compete a essas Faculdades, também, fornecer à terceira idade conhecimentos para uma socialização plena, tanto com elementos do seu próprio grupo quanto com seus familiares (netos, filhos, sobrinhos-netos etc.), além de lhe propiciar a oportunidade de realizar os exercícios pertinentes à sua condição de idoso, fazendo com que mantenha sua forma física saudável.

É desta forma que se está propondo um novo currículo para as Faculdades da Terceira Idade. Estes cursos, que tradicionalmente se realizam três vezes por semana, seriam divididos em quatro atividades:

a) atividades físicas - monitoradas pelos docentes e discentes das Faculdades de Biomédicas e de Educação Física;

b) atividades mentais - constituídas basicamente de processos que permitam o exercício da memória, do raciocínio e da manipulação estética, com a utilização de várias oficinas culturais, tais como: oficinas de jogos (jogo de xadrez, paciência), oficinas de técnicas orientais (origami, ábaco, ikebana etc.), oficinas de pintura, artesanato etc. Ressalte-se que estas atividades poderiam ser grandemente beneficiadas com a utilização de microcomputadores;

c) atividades educativas - baseando-se no ensino formal, apresentação de assuntos de interesse do grupo;

d) atividades operacionais - apresentação das novas tecnologias e dos equipamentos mais usuais na vida do cidadão, sua operacionalidade e formas mais práticas da convivência do idoso com as gerações sucedâneas.

O conteúdo de cada uma destas atividades deverá ser composto de uma parte fixa, determinada pela própria característica do curso e por uma parte variável, que deverá ser discutida no início de cada período pelos integrantes das classes e seus respectivos coordenadores docentes. Desta forma se poderá utilizar os próprios alunos, que possuam conhecimentos amplos sobre um assunto específico, para serem os docentes naquele instante.

Seria interessante, conforme se pratica nos cursos regulares, a formação de uma espécie de Centro Acadêmico para a terceira idade, que se encarregaria de promover atividades sociais e de convivência, sob a supervisão da coordenação da Universidade.

Uma experiência bastante importante foi a realizada na Universidade de Taubaté (Unitau), campo propício para as aplicações práticas, dentro do Programa Redescobrin-

4. A Universidade de São Paulo (USP) abriu em fevereiro de 1994 inscrições para pessoas da terceira idade, oferecendo cursos regulares nas áreas de exatas, humanas e biológicas, em seus campi da Capital e do Interior. No segundo semestre de 1996, a Universidade do Estado de São Paulo (Unesp), campus de Guaratinguetá, iniciou a primeira turma do projeto da Faculdade da Terceira Idade. Podem se inscrever gratuitamente pessoas com mais de 45 anos de idade, de qualquer nível social ou grau de escolaridade. 
do a Matemática, coordenado pela Profa. Eliana Maria Guedes, no projeto denominado Geração de interesse e desenvolvimento pelas Ciências exatas na terceira idade.

Em janeiro de 1997 a FEBASP, Faculdade de Belas Artes de São Paulo, implantou seu curso para a terceira idade, o qual denominou de Faculdade Aberta para a Terceira Idade, tendo como objetivo principal propiciar aos elementos desta faixa etária se desenvolverem num mundo tecnológico-informatizado, não pela obrigação de atender requisitos formais e avaliativos dos cursos regulares, mas pelo estímulo que os motivem à compreensão das Ciências exatas e tecnológicas.

O reforço matemático é uma constante nestes cursos, fundamentado num processo metodológico eclético, partindo do estudo do conhecimento de cada inscrito. Oferece oficinas e palestras sobre plantas medicinais, psicologia, educação física na terceira idade, palestras médicas, geometria das dobraduras, o desenvolvimento matemático (apelidado de a matemática de nossos netos) e origami, entre outros.

A preocupação do idoso com relação à informática concentra-se continuamente em analisar o que se deve aprender, se vale a pena, se é compreensível, se se é capaz de sus-

Resumo: Os autores destacam a importância de os idosos terem acesso ao aprendizado e ao desenvolvimento de suas sensibilidades para o uso das novas tecnologias presentes no cotidiano. O Brasil já apresenta índices consideráveis de envelhecimento populacional, tornando ainda mais importante o desenvolvimento de experiências na área do ensino de informática para habilitar os mais idosos, ajudando-os a viver melhor. As Faculdades para a Terceira Idade têm se mostrado uma alternativa.

Palavras-chave: Informática, idosos, inclusão social, novas tecnologias tentar esse interesse e se esse conhecimento será útil para melhorar a vida no presente.

Enfim, o que o computador pode significar em melhoria da qualidade de vida para os mais velhos, pois como qualquer outra ferramenta, ele pode ser mal utilizado.

Adultos que se vêem praticamente obrigados a lidar com máquinas geralmente se surpreendem e por vezes se amedrontam. Neste momento é importantíssimo que sejam respeitadas as diferenças individuais, que deverão nortear o aprendizado, segundo objetivos específicos, e que devem ser bem definidos pelo usuário.

Uma reforma no processo ensinoaprendizagem, sob diversos aspectos, tornase urgentemente necessária, sintonizada com as nossas principais carências e valendo-se desse autêntico arsenal de conhecimentos, insights e procedimentos surgidos nos últimos anos, sem perder de vista o que aconteceu e está acontecendo, quer em países altamente desenvolvidos, quer em nações em via de desenvolvimento.

Busca-se ensinar para a vida, com a escola e/ou apesar dela, sendo importante que as pessoas pensem e se expressem com clareza, saibam onde encontrar informações, saibam solucionar problemas e tomar decisões.

Abstract: The authors discuss the importance of the elderly having access to learning and to developing their sensitiveness to the usage of the new technologies that are present in their daily lives. Brazil already presents considerable populational aging, making it ever so much more important to develop experiences in the computer science teaching area in order to give the elderly skills and to help them live better. The Colleges dedicated to the Later Life have been a good alternative.

Keywords: Computer science, elderly, social inclusion, new technologies 